\title{
El necesario abordaje interdisciplinario del fenómeno del consumo. Sociología, politica y ambiente
}

\section{The Necessary Interdisciplinary Approach of the Phenomenon of Consumption. Sociology, Politics and Environment}

Carlos Eduardo Tambussi*

http://dx.doi.org/10.21503/lex.v13i15.718

* Abogado, Universidad de Buenos Aires (1991), Procurador Adjunto de Asuntos Patrimoniales y Fiscales del Gobierno de la Ciudad Autónoma de Buenos Aires (2010-2012). Profesor adjunto regular de la Universidad de Buenos Aires, Facultad de Derecho. Cátedra: Dr. Agustín Gordillo. Asignatura: Derechos Humanos y Garantías. Profesor a cargo del curso Protección Constitucional de Consumidores y Usuarios del Ciclo Profesional Orientado en la Facultad de Derecho (UBA). Docente en seminarios y cursos de posgrado sobre derechos de consumidores y usuarios. Miembro del Instituto de Derecho de Usuarios y Consumidores del Colegio Público de Abogados de la Capital Federal. Presidente de la Comisión de Derecho del Consumidor de la Asociación de Abogados de Buenos Aires. Correo electrónico: cetambu@uolsinectis.com.ar

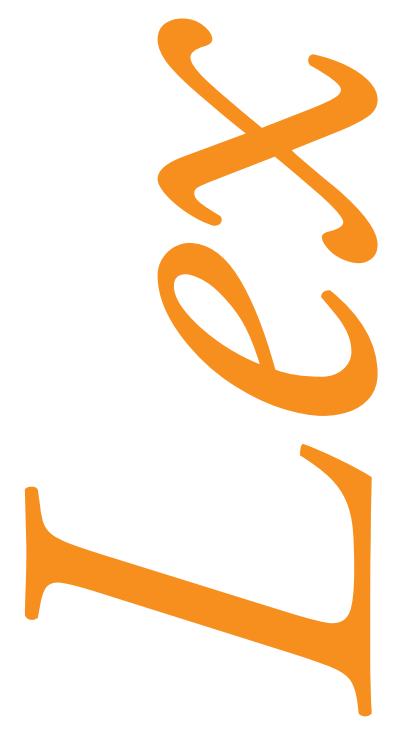




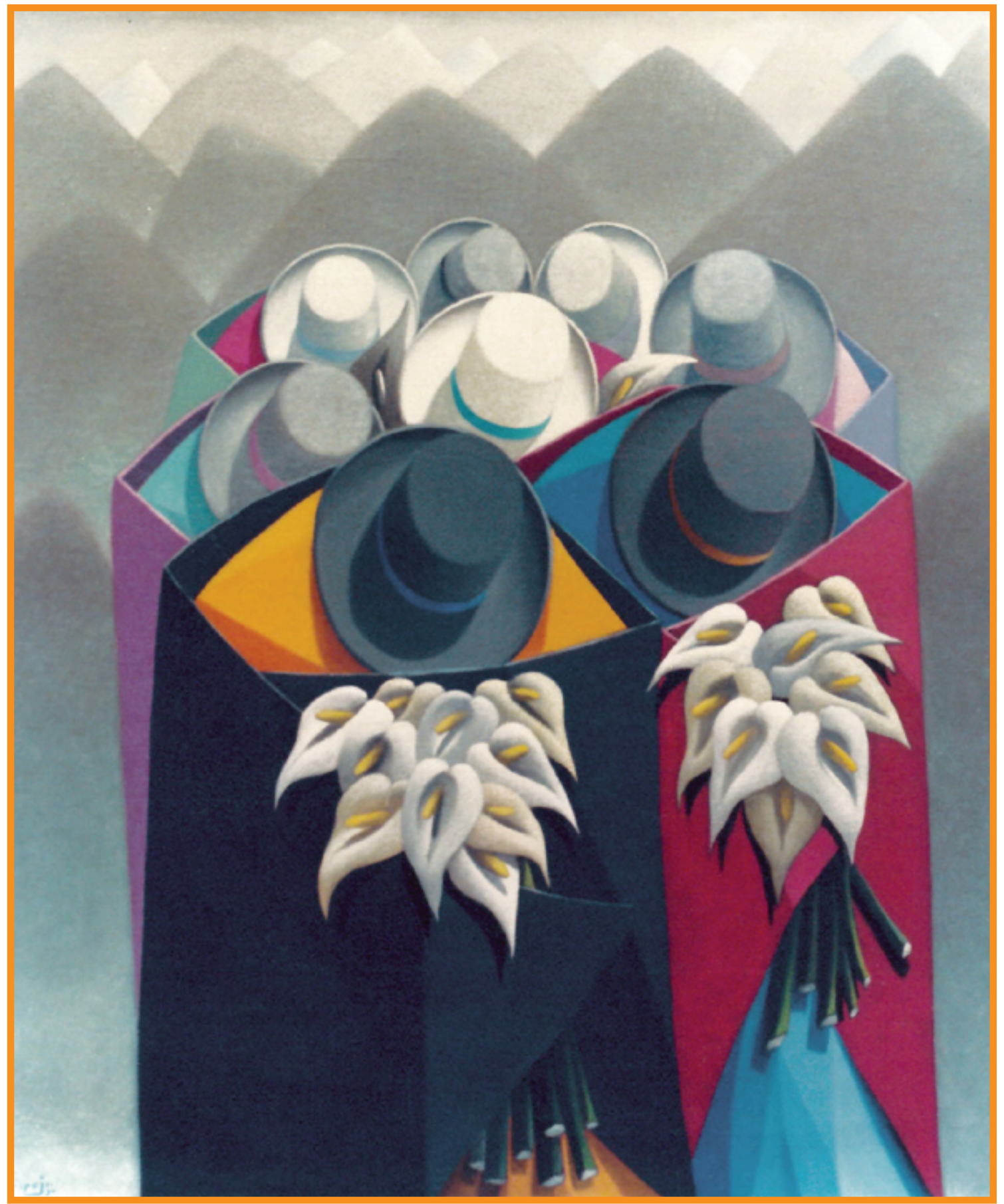

Floristas de cartuchos. 


\section{RESUMEN}

El propósito de este artículo es proponer y exponer aspectos provenientes de otras ciencias, distintas a la jurídica, para alcanzar una visión completa del derecho de usuarios y consumidores, a los efectos de una comprensión fundamental para los objetivos regulatorios, para los criterios de aplicación de sus normas a la hora de decidir los conflictos, y para contribuir a su estudio y profundización, en el complejo entramado de relaciones sociales comprendidas en el fenómeno inevitable que implica el consumo para los seres humanos en los tiempos que corren.

Palabras clave: consumo, análisis multidisciplinario, globalización, derecho, sociología, economía, politica.

\section{ABSTRACT}

The purpose of this paper is to propose and present aspects from other sciences, other than legal, to achieve a complete view of the right of users and consumers, to the effects of a fundamental understanding of the regulatory objectives, for application criteria of its rules for deciding conflicts, and to contribute to the study and exploration in the complex network of social relations including the inevitable phenomenon that involves the consumption for humans in these times.

Key words: consumption, multidisciplinary analysis, globalization, law, sociology, economics, politics. 



\section{INTRODUCCIÓN}

El Derecho de Consumidores y Usuarios necesita insoslayablemente complementarse con una visión interdisciplinaria. ${ }^{1}$ Los operadores jurídicos necesitan de un enfoque multifacético que les permita una mejor comprensión del fenómeno, tanto a la hora de elaborar las normas como de invocarlas, aplicarlas o proponer su modificación. Sin el auxilio de otras ciencias, la dimensión del consumo se parcializa y se aleja de la realidad. El objetivo de este trabajo es sintetizar los puntos de vista que coadyuvan a una adecuada comprensión del universo del consumo, para complementar y fortalecer el esfuerzo jurídico por regularlo, preservarlo y perseverar en su desarrollo.

Se propicia, entonces, un abordaje que mediante conocimientos integrados "sintetice un complejo cognoscitivo que permite manejar con eficiencia las variables múltiples que configuran la complejidad del objeto en tratamiento", ${ }^{2}$ toda vez que es evidente en el derecho del consumidor que la materia "no se limita a aspectos meramente jurídico-normativos, sino que comprende problemáticas sociales, culturales, económicas, políticas, etc., interactuantes, las que, en consecuencia, no pueden resolverse adecuadamente desde posiciones sesgadas —es decir, parciales y fragmentarias, parcelarias—: ninguna disciplina en particular lograría per se dar respuesta eficaz a tales desafíos" ${ }^{3}$

\section{Visión sociológica. Globalización}

No es intención de esta aproximación hacer un tratado sobre el fenómeno de la globalización. Sí, en todo caso, intentar definirlo y encuadrarlo en sus características fundamentales.

Desde luego que esa multivisión se da en el marco de la misma ciencia jurídica: "Reconocemos carácter interdisciplinario al llamado derecho de los consumidores; la problemática, en consecuencia, supera las normas del Derecho Civil, Comercial, Procesal, Penal, Administrativo, etc., para comprenderlas e integrarlas sistemáticamente”. Cámara Civil, Comercial, Laboral y de Minería de la Provincia de Chubut Sala B (Graciela Mercedes García Blanco Nélida Susana Melero Marta Susana Reynoso de Roberts) A. A. SA Y G. M. de A. SRL en autos: "L. T. SRL (Z., M. G.) c/A. A. Y C. s/ Reclamo s. Apelación Art. 7 LEY 4219 Sentencia, 56-C-10 del 11 de noviembre de 2010. En Sistema Argentino de Informática Jurídica. Identificación SAIJ: Q0024134.

2 Alfredo Mario Condomí. "Primeros pasos en el derecho del consumo. Segunda parte Algunos principios". Recuperado el 8 de febrero de 2015 desde http://www.infojus.gob.arlalfredo-mario-condomi-primeros-pasos-derecho-consumo-segundaparte-dacf130328-2013-10-25/123456789-Oabc-defg8230-31fcanirtcod

3 Ibidem. 
Como definición de un momento histórico, la palabra globalización nace luego de la caída del Muro de Berlín, hecho simbólico y culminante de la desaparición política del llamado socialismo real ${ }^{4}$ con la disolución de la Unión Soviética y el fin del régimen socialista en los llamados países de Europa del Este y la aparente consolidación del capitalismo de mercado como sistema económico mundial.

Triunfador en esa batalla, gritó a quien quisiera oírlo el llamado fin de las ideologías, a partir del cual el planeta (globalización quizás alude a la forma geométrica de la Tierra) queda (presuntamente para siempre) regido por un sistema común, democrático a lo occidental en lo político, y capitalista en lo económico, quedando solo algunas islas (literal y ejemplificadoramente hablando) refractarias del (no tan) nuevo orden.

Globalización está significando la homogeneización e internacionalización de los patrones de consumo y producción. Este fenómeno pervive en unificar las necesidades creadas de la gente, estableciendo las mismas pautas y los mismos usos a nivel mundial, diluyendo las identidades nacionales que se definían, también, por el consumo. Consumir lo propio constituía una parte de la pertenencia que se ha perdido, en esta idea que propone que todos consumamos lo mismo. ${ }^{5}$

Implica, a su vez, una transformación constante en la tecnología de producción y diseño de los objetos, generando una ampliación muchas veces artificiosa e inducida de los deseos y expectativas materiales. La obsolescencia acelerada de los productos más vinculados con adelantos tecnológicos, dosificada en forma convenientemente y al servicio del marketing provoca una sensación a veces artificial de retraso y necesidad artificial de realizar un nuevo consumo para actualizarse.

La globalización acentuó la interdependencia de los movimientos de capital financiero, que son rigurosamente controlados por los países dominantes y los organismos del crédito internacional. Ya no existe — definitivamente - más capital con patria; el flujo de dinero es más un juego de corporaciones o de bloques que la resultante de políticas económicas o fiscales de países políticamente soberanos.

Por consiguiente, y para abundar argumentalmente en el excusario habitual de los funcionarios, se genera una creciente exposición interna o apertura de economías, donde las

\footnotetext{
Aunque preferimos llamarlo, junto con Eric Hobsbawn, "socialismo realmente existente".

5 "Se asigna un ordenamiento de preferencias a una persona, y cuando es necesario se supone que este ordenamiento refleja sus intereses, representa su bienestar, resume su idea de lo que debiera hacerse y describe sus elecciones... En efecto, el hombre puramente económico es casi un retrasado mental desde el punto de vista social. La teoría económica se ha ocupado mucho de ese tonto racional arrellanado en la comodidad de su ordenamiento único de preferencias para todos los propósitos" (Amartya Sen. "Los tontos racionales: una crítica de los fundamentos conductistas de la teoría económica”. Filosofía y teoría económica. F. Hahn \& M. Hollis. México: FCE, 1986).
} 
crisis repercuten con efecto cascada afectando sectores aparentemente desligados del punto crítico (geográficamente), creándose la necesidad de recetas o políticas comunes a lugares con quizás situaciones muy distintas. En suma, la globalización encierra una "interacción funcional de actividades económicas y culturales dispersas, de bienes y servicios generados por un sistema con muchos centros". ${ }^{6}$

Políticamente, conforme parece generalmente aceptado, globalización implica el sostenimiento (como única alternativa que permite dejar hacer al mercado) de la democracia liberal como pensamiento predominante. Concomitantemente, el alejamiento de la política de las realidades sociales y su lentitud para la apreciación, diagnóstico y solución de los problemas cotidianos (sin contar la corrupción en esta parte del esbozo) acarrean un descreimiento profundísimo de la utilización de la participación política (y de la política como tal) como herramienta válida para las correcciones necesarias. Hay un traslado de las esperanzas sociales hacia otras formas de agrupación, que van desde las organizaciones no gubernamentales (ONG) hasta congregaciones religiosas. Los modelos sociales pasan más por el espectáculo, el deporte o por hasta el delincuente más audaz, que por los tradicionales grandes repúblicos sobre cuyas biografías las naciones educaron a sus hijos. En nuestros países latinoamericanos, el errante desarrollo de nuestras democracias, su creciente inestabilidad y discontinuidad de líneas básicas o directrices, la desaparición de una generación política e intelectual producto de las dictaduras de los setenta y de los ochenta originaron un subproducto de escepticismo, sensación de eterna transitoriedad y un temor al compromiso y a la participación del que solo en algunos casos extremos despertamos, y de cuyos resultados pocas veces sabemos cosechar.

La globalización trajo fuerte aumento del desarrollo tecnológico y consiguiente incremento del poder de sus propietarios, los dueños del desarrollo. Lo que se tiene se vuelve a cada instante obsoleto o fugaz. Cada vez es artificiosamente demasiado tarde más temprano.

En cuanto a las condiciones de trabajo, el fenómeno es el de la flexibilización (antes bien, precarización), condimentada con las pérdidas de empleo ocasionadas por la sustitución de la mano de obra humana por tecnología. "El modo neoliberal de hacer la globalización consiste en reducir empleos para reducir los costos, compitiendo entre empresas transnacionales que no se sabe desde dónde se dirigen, de manera que los intereses sindicales y nacionales casi no pueden ejercerse".?

Culturalmente, la globalización masificó y universalizó el alcance de los medios de comunicación, reduciendo a la apreciación mediática los hechos sociales significativos, con comunicación inmediata y proyección mundial de los patrones culturales estandarizados que se buscan imponer.

\footnotetext{
${ }^{6}$ Néstor García Canclini. Consumidores y ciudadanos. Conflictos multiculturales de la globalización. México: Grijalbo, 2000. Ibidem.
} 
Consecuentemente con lo anterior, se erosionaron las identidades culturales nacionales, presentándose al nacionalismo (aun el bien entendido) como cosa del pasado, en todo cuanto se oponga a la homogeneización imperante, es decir, la modernidad (y ya nos desactualizamos, pues se habla de posmodernidad), por oposición a lo antiguo, como se califica a cualquier cuestionador. Las ideas tienen fecha de vencimiento, sin indagar por la fecha de nacimiento de la imperante. Existe, por supuesto, el derecho a mudar de ellas, según las circunstancias o sus posibilidades de éxito.

Globalización conlleva el surgimiento y consolidación de bloques económicos transnacionales que se consolidan regionalmente y compiten entre sí.

Su propuesta moral es la de la exaltación del individualismo y el éxito material (eficacia comercial) como meta personal y signo de reconocimiento social. Eficacia comercial y éxito material implican posesión de cosas, acceso a bienes de consumo que se adquieren en el espacio deificado llamado mercado. Siguiendo a Guimaraes, ${ }^{8}$ coincidiremos en que el mercado se expandió en el tiempo del surgimiento del liberalismo, como un agente civilizador (y hasta con consecuencias igualitarias), para oponerse al privilegio de la aristocracia; como transformador de las relaciones sociales hacia niveles superiores de sociabilidad y progreso económico.

Pero en el marco descrito, los resultados de la creencia en la autorregulación del mercado lo evidencian las cifras de pobreza, marginalidad, y tecnicismos varios que se emplean para mensurar la situación de los que han quedado fuera del acceso al mismo y al consumo.

A la inversa, es en estos tiempos al Estado al que se le debe reconocer como "el contrapunto bondadoso para contener las fuerzas ciegas del mercado, que abandonadas a sí mismas son incapaces de lograr la felicidad humana". ${ }^{9}$ Viene conveniente entonces asimilar la experiencia y evitar la vuelta al Estado sobredimensionado, tecnológicamente atrasado, ineficiente y endeudado. El equilibrio propuesto solo puede ser encontrado por la política, por una nueva política. Y en esto debe ponerse especial énfasis ya que en el vacío que la política tradicional ha dejado (provocado por su desprestigio tan bien ganado como en otros aspectos inmerecido), "se insertan los grupos económicos, los medios de comunicación y los resquicios oligárquicos, travestidos en agentes de la modernidad basada en la ideología neoliberal". ${ }^{10}$ Frente a esto, se esgrime la verdad objetiva de que no existen postulaciones capaces de defender sólidamente la tesis que la elaboración y gestión de la vida pública pueda realizarse sin la mediación de la política, para superar la pobreza, la marginación y la desigualdad.

8 Roberto P. Guimaraes. "Modernidad, medio ambiente y ética: los dilemas del desarrollo”. Ambiente \& Sociedade, 2 (1998, primer semestre).

Ibidem.

10 Ibidem. 
Este diagnóstico lleva consigo la necesidad de replantear la relación Estado-MercadoSociedad a través de la acción política (efectiva, legisladora, concientizadora), para lo cual el mundo de los asuntos públicos tiene necesariamente que salir de las reglas del marketing, el espectáculo y la corrupción.

García Canclini define al consumo como "el conjunto de procesos socioculturales en los que se realizan la apropiación y los usos de los productos". ${ }^{11}$ Así, el consumo expresa una realidad sociopolítica interactiva. Consumir es, en ese pensamiento, participar en un escenario de disputas por aquello que la sociedad produce y por las maneras de usarlo. El consumidor sale al mercado forzosamente obligado a satisfacer sus necesidades, desde las más simples hasta las más suntuarias —aquellos que están en condiciones de hacerlo-.

En ese panorama, mencionaremos dos aspectos que son distintivos del signo de los tiempos:

La inducción cultural del consumo hace que se confundan necesidades con deseos y que en algunos casos consumos no imprescindibles se conviertan en demandas culturalmente condicionadas. El consumidor no es un ser aislado, sino que se encuentra inmerso y condicionado socialmente. Hay también aspectos iconográficos y estéticos en el consumo, dado que la posesión de cosas enuncia hacia afuera un signo de estatus, una personalidad determinada, una repercusión social. Se construye un paradigma donde los pertenecientes comen, se divierten, estudian, se visten, habitan, viajan, de una manera determinada, consultan o consumen determinados medios de comunicación. La sociedad humana impone a sus miembros —otra vez- principalmente la obligación de ser consumidores. La forma en que esta sociedad moldea a sus integrantes está regida, ante todo y en primer lugar, por la necesidad de desempeñar ese papel: la norma que les impone, la de tener capacidad y voluntad de consumir. ${ }^{12}$

La obsolescencia programada, que es una práctica empresarial que consiste en utilizar técnicas para acortar la vida de un producto con el fin de que el consumidor tenga que reemplazarlo, y comprende la utilización de piezas o repuestos pensados con vida útil muy limitada para convertir al producto inutilizable, obsoleto o inservible en un lapso premeditado, a partir de lo cual la fabricación de los repuestos se discontinua, y deja la única posibilidad de acudir al producto nuevo, lógica y sensiblemente más caro.

El primer mecanismo es inductivo del inconsciente, y trajo consigo el surgimiento del fenómeno del sobreendeudamiento del consumidor, que puede llegar a sobrepasar su capacidad de pago en aras de una carrera contra múltiples consumos muchas veces suntuarios.

11 Néstor García Canclini. Op. cit.

12 Esteban J. Arias Cáu - Sergio S. Barocelli. "El sobreendeudamiento del consumidor y la adicción al consumo" Microjuris (octubre 2013), cita: MJ-DOC-6461-AR | MJD6461. 
El segundo, versa sobre una estimulación artificial de la demanda, mediante el arrojo al consumidor a comprar (de modo programado) productos nuevos si desea seguir cubriendo la necesidad en juego. Ese sentimiento obligatorio inducido se traduce, además del precio mucho mayor de la novedad, con las muchas veces dudosa o significativa calidad de la innovación contenida en el producto de repentina y publicitada aparición como innovador.

\section{Visión política}

Desde que el Derecho es poder político que se juridiza, la existencia de normas sobre Derecho del Consumidor, como todas las del ordenamiento jurídico, se debe a una decisión política traducida en el funcionamiento de los mecanismos democráticos, y su persistencia a la permanencia de esa decisión política en el tiempo, o los impulsos renovadores o transformadores que generen las ideas y la adaptación a los cambios.

Desde la génesis misma del Derecho del Consumidor hasta las innovaciones, pasando por su jerarquía normativa en el sistema de un país determinado, hasta la efectividad de sus mecanismos de garantías para protegerlo, son el resultado de una decisión política. Ella determina también con qué jerarquía administrativa el Estado se va a preocupar del control, vigilancia y sanción en la defensa de estos derechos, y por último, pero no finalmente, el grado de independencia que tengan las acciones estatales en materia de defensa del consumidor, de lo que sean las decisiones políticas del gobierno de turno. No es lo mismo que la autoridad de aplicación de las normas de defensa del consumidor, por ejemplo, se encuentre custodiada por organismos independientes de la estructura general de la administración pública, que las mismas sean llevadas a cabo por funcionarios independientes o extrapoder, como la Procuraduría Federal en el caso mexicano, donde el criterio de la agencia estatal es permanente en defensa de los derechos de consumidores y usuarios en una constante vinculada a una política de Estado, sin depender de la ideología de mayorías circunstanciales o gobiernos de turno.

Es entonces que la política participa de la creación, diseño y alcance de las normas y garantías de defensa del consumidor, y las conduce tanto como vehículo de servicio público de protección, como también como instrumento de la implementación de políticas interesadas al compás de los vaivenes de la política económica que se lleve adelante.

El caso argentino es particularmente interesante.

La Ley 24.240 de Defensa del Consumidor (en adelante LDC) fue sancionada por el Congreso Nacional el 22 de septiembre de 1993 y parcialmente promulgada con fecha 13 de octubre de 1993, mediante el decreto 2089/93, oportunidad en la cual se ejerció por el Poder Ejecutivo el veto de aspectos fundamentales del articulado sancionado por el Congreso utilizando de forma constitucionalmente dudosa esa atribución del veto, buscando disminuir 
los niveles de protección, eliminando la gratuidad del sistema judicial de reclamos ${ }^{13}$ (artículo 53 texto original), y los efectos erga omnes de las sentencias en las acciones colectivas del artículo 54 original. ${ }^{14}$

\section{El veto parcial que mencionamos se refirió fundamentalmente ${ }^{15}$ a:}

- La llamada garantía legal (artículo 11) y al artículo 13 que consagraba la responsabilidad solidaria. El argumento esgrimido fue que la temática ya se encontraba regulada en los vicios redhibitorios del Código Civil y que "la misma cercenaría la libertad del oferente de poner en el mercado productos con o sin garantía, y la del consumidor de elegir unos u otros, y significaría como tal limitar el acceso al mercado de ciertos productos, en general de bajo costo o de uso rápidamente descartable o de rezago, en perjuicio del consumidor”. Esto privó a los consumidores de la posibilidad de accionar contra toda la cadena de comercialización del producto.

13 El Poder Ejecutivo utilizó a tales fines el argumento de que la gratuidad resultaba innecesaria atento la existencia y regulación del beneficio de litigar sin gastos en las normas procesales. También se habló (en plena ofensiva del Ministro Cavallo contra los abogados) de la "industria del juicio" que la gratuidad generaría, cuando —en realidad— con inteligencia y buena intención se hubiera podido aplicar la gratuidad hasta cierto monto de reclamo, para evitar que consumos suntuarios resultaran beneficiarios de litigar sin gastos.

14 El veto en este punto se fundamentó en el recóndito argumento de que el efecto erga omnes afecta la garantía de defensa en juicio.

15 El veto completo involucró los siguientes artículos legislativos y temas involucrados: Artículos fundamentales vetados: 1) Artículo 10, inciso c), que imponía como contenido del documento de venta e nombre y domicilio del fabricante, distribuidor o del importador cuando correspondiere". Argumento: implicaría entorpecer el comercio de modo incompatible con la normal actividad económica, y con los requisitos de la documentación previstos a los fines fiscales, en particular en las operaciones cotidianas del comercio minorista, más aún en los casos de ventas que incluyan varios artículos. Por vía reglamentaria pudo haberse previsto alguna manera de hacer inmediata y pronta la individualización de partícipes (y por ende responsables) ya sea en las instrucciones de uso, en la garantía, si existiera o en el envoltorio o embalaje mismo, lo cual ya existe y está vigente pero no siempre se cumple. 2) Artículo 11: "La garantía legal tendrá vigencia por seis (6) meses a partir de la entrega, pudiendo las partes convenir un plazo mayor". Argumento: cercenaría la libertad del oferente de poner en el mercado productos con o sin garantía y la del consumidor de elegir unos u otros y significaría como tal limitar el acceso al mercado de ciertos productos, en general de bajo costo o de uso rápidamente descartable o de rezago, en perjuicio del consumidor. 3) Artículo 13: "Son solidariamente responsables del otorgamiento y cumplimiento de la garantía legal, los productores, importadores, distribuidores y vendedores de las cosas comprendidas en el artículo 11". 4) Artículo 14: (parte de su penúltimo párrafo) "la falta de notificación, no libera al fabricante o importador de la responsabilidad solidaria establecida en el artículo 13". En este caso sin ningún argumento, dejando inerme al consumidor no advertido que debía notificar que compró el producto, para que la garantía sea efectiva, cuando es el comerciante quien está en inmejorables condiciones de entregar al productor o importador esta notificación, ya que ello no le implica ningún gasto o incomodidad adicional, pues su trato con ellos es permanente y continuo. 5) Artículo 40 (Responsabilidad objetiva y solidaria): En los considerandos se hace hincapié en que el proyecto establece un sistema de responsabilidad por daños general y no discriminado para cierto tipo de productos, para la cadena de producción, distribución y comercialización, sin posibilidad de excluir tal responsabilidad en los casos en los cuales se justifiquen que no ha mediado culpa del agente. Se dijo también que la norma reseñada del Art. 40 con relación al régimen de responsabilidad por daños, por vicio o defecto de la cosa o de la prestación del servicio, redundaría igualmente en un aumento del precio de los productos y en menor competencia en los mercados, objetivos claramente reñidos con el programa económico del Gobierno Nacional y perjudicial para el interés de los consumidores cuya defensa se persigue. 6) Artículo 53: (último párrafo): "Las actuaciones judiciales que se inicien de conformidad con la presente ley gozarán del beneficio de justicia gratuita". Argumento: el beneficio de litigar sin gastos, o carta de pobreza, se encuentra regulado en forma específica por las leyes provinciales locales, conforme a los requisitos establecidos en ellas, y torna innecesaria la previsión del artículo 53, la que por otra parte podría alentar la proliferación de acciones judiciales injustificadas. 
- Se extendió también al artículo 40, relativo a la responsabilidad solidaria por daño causado por productos elaborados. ¿Era esto una rareza nacional? Nada más lejano: En los Estados Unidos, la Consummer Product Safety de 1972 y la Uniform Product Liability Act de 1979 han entendido que la responsabilidad del fabricante se extiende a todos los que integran la cadena de comercialización, y en el caso de la Unión Europea la Directiva 85/374 prevé la responsabilidad solidaria de los sujetos equiparados al productor por intervenir en la cadena de comercialización, así como el carácter objetivo de esa responsabilidad, permitiendo al consumidor elegir contra quien recurrir (artículo 5). También estaba contemplada en el Código del Consumidor Brasileño, ley 8.078/90 (artículo 12). El argumento fue, otra vez, el pretendido combate contra la industria del juicio y la corporación abogadil.

De modo que se buscó morigerar las posibilidades de aplicación de la ley en su implementación, en su utilización directa como instrumento y vehículo garantista, traicionando los fines generales, mas allá incluso de los vericuetos que se utilizaron para impedir al Congreso la insistencia necesaria, de cuya voluntad a tales fines nos quedan dudas. La ley fue un oasis en tiempos de desregulación, liberalismo ortodoxo y fiesta del abandono de lo público, pero el poder no vio pasar desapercibida su sanción y buscó disciplinar a la criatura desde el alumbramiento. ${ }^{16}$

Más adelante, en el año 2008 y bajo el gobierno del mismo signo que el regente en la actualidad, se plasmó una significativa reforma por la Ley 26.361 del 12 de marzo de 2008, que, pese a su poca organicidad y deficiente técnica legislativa, ${ }^{17}$ fue la última modificación participativa y significó un gran avance en materia de consagración de derechos y afianzamiento del garantismo a favor de consumidores y usuarios, tendiendo hacia una profundización de la operatividad del artículo 42 de nuestra Constitución Nacional.

No obstante, el proyecto de ley aprobado por el Congreso argentino en esa oportunidad eliminaba la subsidiariedad de las normas del derecho del consumo en conflictos derivados del servicio de transporte aéreo, que establecía el artículo 63, propiciando su derogación, por no existir al respecto "ninguna justificación técnico-jurídica ni de sana política de consumo", ${ }^{18}$ tratándose de una actividad que debe ser alcanzada por el derecho del consumo (las aerolíneas son proveedoras y los pasajeros sin duda consumidores) sin que haya mérito para la excepción

16 Ver: Sebastián Pablo Facioni. "El veto y promulgación parcial a la Ley de Defensa del Consumidor y del Usuario es inconstitucional, tanto es su aspecto formal como sustancial”. El Dial. 5 de mayo, 2006, Suplemento de Derechos de Consumidor.

17 Desde el estricto punto de vista de la técnica legislativa, se ha criticado a la reforma: a) La carencia de "título" en la misma, cuestión que en la doctrina extranjera se trata estableciéndose que las leyes deben intitularse con referencia a La Ley modificada; b) la ausencia de epígrafes o títulos en los artículos que destaquen su contenido; c) la falta de "capítulos" u organización sistemática, entre otros. (Ver: Luis F. P. Leiva Fernández. "La Ley 26.361 de afuera hacia adentro". Suplemento Especial La Ley "Reforma de La Ley de Defensa del Consumidor” (abril de 2008), p. 67 y siguientes.

18 De los fundamentos del proyecto de la Cámara de Diputados. 
por su naturaleza. ${ }^{19}$ De no haber existido el veto a ese artículo, las empresas aerocomerciales hubieran debido cumplir con el deber de información precisa, clara, cierta, detallada, del artículo $4^{\circ}$ de la Ley de Defensa del Consumidor, y cumplido con sus previsiones en todos los aspectos relativos a la contratación del vuelo y el servicio en general. ${ }^{20}$

El Decreto de promulgación parcial Nro. 565/2008 observó la normativa sancionada por el Congreso en este punto con fundamento en que:

a. Las leyes de defensa del consumidor (nota nuestra, confusa mención en plural) "no constituyen normas de fondo sino que resultan reglas protectivas y correctoras, siendo complementarias y no sustitutivas de la regulación general contenida en los códigos de fondo y la legislación vigente".

b. Las normas de consumo se aplican como controladoras de las "cláusulas contractuales predispuestas en los contratos de adhesión, cuando el Estado Nacional no interviene mediante un control genérico en actividades como el transporte aerocomercial por medio de una Autoridad de Aplicación específica, con cuerpos normativos especiales (Código Aeronáutico, Reglamentación del Contrato de Transporte Aéreo y Tratados Internacionales que integran el Sistema de Varsovia), con controles tarifarios, de autorizaciones de los servicios a prestarse, de habilitaciones del personal, de aeronaves, de talleres de mantenimiento y de horarios, rutas, frecuencias y equipos con los cuales se cumplirá”.

c. En los países de mayor tráfico aéreo, la actividad se rige por reglamentos propios y en nuestro caso el derecho de los usuarios del transporte aerocomercial está reglamentado en la Resolución No 1532 de fecha 27 de noviembre de 1998 del antiguo Ministerio de Economía y Obras y Servicios Públicos, "Condiciones Generales del Contrato de Transporte Aéreo".

d. Resalta la necesaria integralidad, uniformidad, autonomía e internacionalidad del Derecho Aeronáutico, por la cual cada país no cuenta con la potestad de regular la materia en su Derecho Interno, en desmedro o en diferencia de los acuerdos internacionales, so pena de desnaturalizarse el sistema regulatorio interestatal del tráfico aéreo, y la consecuente inseguridad jurídica que esto generaría, citando en apoyo jurisprudencia británica y norteamericana en el sentido señalado y máxime teniendo en cuenta que se trata de un sector como el tráfico aerocomercial que ha sido declarado en estado de emergencia por el Decreto No 1654 de fecha 4 de septiembre de 2002 y el Decreto No 1012 de fecha 7 de agosto de 2006.

19 La derogación es fuertemente criticada por Carlos María Vasallo, en La Ley 2007 C, p. 1289, "El Proyecto de reforma de la Ley de Defensa del Consumidor y el Transporte Aéreo".

20 Piénsese en la cantidad de inscripciones en inglés, más signos, símbolos y abreviaturas que existen en los pasajes aéreos, que los hacen inentendibles para buena parte de la gente. En la actualidad, la casi inexistencia del "pasaje en soporte papel”, reemplazado por la reserva y constancia virtual de adquisición de un pasaje, deberá proporcionar por el sistema electrónico la información completa que la ley tutela. 
e. Por último, añade que la observación efectuada no altera el espíritu de la reforma, por lo que con esa sola observación (ver texto del Decreto en el anexo de esta obra) se promulga la Ley 26.361 .

La finalidad política encubierta fue la de no sujetar a la aerolínea de bandera a las normas de consumo, sin perjuicio de la quizá razonable exclusión del transporte aéreo internacional, dada la vinculación de la Nación Argentina por tratados internacionales que regulan la aviación civil. En cambio, nada impedía, y en esta interpretación el veto altera el espíritu de la reforma que se quiere preservar, que se aplicaran las normas de consumo al transporte aéreo interno.

En nuestro pasado muy cercano y reciente, ante la aparición de fenómenos inflacionarios y crecimiento sostenido de precios, el derecho del consumidor en la Argentina tuvo un nuevo embate normativo de cuyas bondades dirá el futuro, mediante la sanción de la unificación del Código Civil y Comercial (Ley 26.994) ${ }^{21}$ que introduce la regulación de los contratos de consumo en un cuerpo normativo unificado, la creación del Sistema de Resolución de Conflictos en las Relaciones de Consumo (Ley 26.993), ${ }^{22}$ la búsqueda de la regulación del mercado mediante la reforma de la Ley de Abastecimiento (20.680) que había sido sancionada en 1974, como un curioso producto de especiales tiempos democráticos, ${ }^{23}$ y finalmente un "Observatorio de Precios y Disponibilidad de Insumos, Bienes y Servicios" y el Programa "Precios Cuidados" (Ley 26.992). La multiplicidad de regulación se completó con la modificación parcial de la Ley de Defensa del Consumidor por el Nuevo Código Civil y Comercial Unificado y por el Sistema de Resolución de Conflictos, que modificó además las Leyes de Defensa de la Competencia y de Lealtad Comercial.

Por lo que en los últimos tiempos el derecho del consumidor y sus normas integradas en la Argentina han merecido especial atención del poder político, modificándose sensiblemente su régimen de garantías, algunos institutos legales, invocándose la defensa del consumidor para la construcción de herramientas de control estatal-social de los precios al consumidor, en tónica con la fisonomía de la política económica imperante.

De modo que la influencia de la decisión política de turno en el mundo del consumo es no solamente determinante sino constante, y acompaña el signo ideológico imperante en un momento determinado, como lo demuestra el caso descrito, que cabalga desde la sanción de una norma intervencionista en tiempos manifiestamente liberales, pasando por hitos de reformas participativas y consensuadas, hasta desembocar en una catarata de normas impuestas por apremiantes circunstancias en base a mayorías parlamentarias reinantes sin

21 Reforma los artículos 1, 8, 40 bis y 50 .

22 Reforma los artículos 36, 40 bis y 45 e introduce el art. 54 bis.

23 Reformada en 2014 por Ley 26.991. 
mayor discusión o debate (excepto respecto a la unificación y reforma de los Códigos Civil y Comercial), todas ellas hechas curiosamente bajo nominalmente el mismo partido político.

\section{Política y ciudadanía. Consumidores ciudadanos}

Habiendo abordado la influencia de la política poder e ideología reinante, nos referiremos a la política desde el lado del consumidor, como sujeto de la ciudadanía y su vinculación con la participación y el nivel de involucramiento e influencia de los consumidores en el sector social.

Sostiene Néstor García Canclini ${ }^{24}$ que "siempre el ejercicio de la ciudadanía estuvo asociado a la capacidad de apropiarse de los bienes y a los modos de usarlos, pero se suponía que estas diferencias estaban niveladas por la igualdad en derechos abstractos que se concretaban al votar, al sentirse representado por un partido político o un sindicato”.

En ciertas formas de la participación política y desde los primeros albores de la democracia liberal, la posibilidad del voto estuvo asociada a las posibilidades de consumo (desde la categoría de vecino necesaria para ser cabildante en tiempos coloniales, hasta la exigencia de cierta renta anual para ser legislador establecida en nuestra Constitución, aún vigente en este punto). El sufragio universal no tiene un siglo de vida en la Argentina (y en su versión completa - comprensiva del voto femenino - unos cuantos años menos), y vino a democratizar a través de la participación política la situación de la población de bajo nivel de consumo, con la que empezó a necesitarse contar para captarla o seducirla si se aspira a niveles de poder importantes.

Además, el surgimiento de los grandes partidos populares argentinos vino de la mano de mayores oportunidades de consumo y un cambio en las características del mismo para los sectores sociales involucrados (la clase media con el yrigoyenismo, y el proletariado urbano con el justicialismo). ${ }^{25}$

En la actualidad, la complejización de los temas y la tecnoburocratización de las decisiones, el traslado de la campaña política del acto público a la televisión, la sustitución del debate doctrinario por la comparación de imágenes, hacen que ante la sensación de que todo se planifica desde instancias globales inalcanzables, una de las pocas autonomías de decisión que queda es el acceso a los bienes que nos provee el consumo.

24 Néstor García Canclini. Op. cit.

25 En la Argentina, el radicalismo Yrigoyenista que llegó al poder en 1916 perduró durante mucho tiempo en el aprecio popular y de la clase media por la conquista del sufragio universal y la consiguiente significación del acceso a la burocracia pública de los sectores medios, de los "hijos de inmigrantes" profesionales o cuasi profesionales por entonces. El justicialismo o peronismo, más nuevo en su fenomenología, y más allá del análisis o valoración política que la diversidad permite a su respecto, aún tiene recuerdos vivos de testigos presenciales de distribucionismo directo y/o de ampliación de las posibilidades de acceso a consumos hasta entonces impensados para los sectores obreros. 
Junto con el descreimiento de la política y de las instituciones, otros grupos participativos cobran gran fuerza. La gente empieza a creer que su representatividad, sus derechos, su información, se reflejan más en las reglas de consumo y en la protección y defensa de las cosas que hacen a su vida diaria que en las normas abstractas de la democracia o en la participación colectiva en espacios de actuación.

Analizando aisladamente mercado y consumo, plantearemos solamente los asuntos con la regla de la eficacia comercial, y la globalización como la manera de llegar más rápido a las ventas. La mirada política ha sido ganada por el mercado, al que se lo vende como más eficaz para organizar las sociedades.

Muchas veces escuchamos que se minimiza al fenómeno del consumo como lugar de lo suntuario y lo superfluo, donde los impulsos primarios de los sujetos podrían ordenarse con estudios de mercado y tácticas publicitarias. Y la ciudadanía se reduce a una cuestión política, donde la gente vota y actúa de acuerdo a sus convicciones individuales.

Sin embargo, ser ciudadano no tiene que ver solo con los derechos reconocidos por los aparatos estatales a quienes nacieron en un territorio, sino también con las prácticas sociales $\mathrm{y}$ culturales que dan sentido de pertenencia y hacen sentir diferentes a quienes poseen una misma lengua y una misma forma de organización y satisfacción de necesidades.

El ejercicio de la ciudadanía, el rol de consumidor ciudadano necesita de la existencia de mecanismos de participación social y de conciencia en lo individual. La democracia social requiere la consolidación de la acción de grupos de consumidores, que unen transversalmente necesidades comunes y que pueden ser el núcleo de una nueva representatividad. A su vez, requiere consumidores consustanciados y exigentes guardianes de sus derechos.

Conjuntamente, los mecanismos de democracia directa (referéndum, consulta popular), los sistemas de participación de los interesados en niveles de decisión (audiencias públicas) y la ampliación de la legitimación activa a nivel judicial para la interposición de acciones colectivas, coadyuvan a formar un punto de partida interesante para esta nueva forma de representar y hacer política (en el sentido amplio de la palabra).

No obstante, la relación cultural no es simplemente de captación entre dominadores hipnóticos y pasivos receptores de avisos. Existen múltiples situaciones que pueden verse a través de otras disciplinas (no solo la económica o la jurídica), y es en ese múltiple enfoque donde debe continuarse con este análisis.

\section{Visión ambiental}

En cuanto al consumo sustentable, como pauta de interpretación y aplicación del derecho del consumo, es un elemento indispensable dada la íntima vinculación entre la noción de 
desarrollo sustentable (expresamente contemplada) y consumo sustentable, que se implican mutuamente.

El concepto de consumo sustentable fue definido por la ONU como el uso de servicios y productos que responden a las necesidades básicas y aportan una mejor calidad de vida al mismo tiempo que minimizan el uso de recursos naturales y de materiales tóxicos así como también la emisión de desechos y contaminantes sobre el ciclo de vida, de manera tal de evitar poner en peligro las necesidades de futuras generaciones (Comisión de Naciones Unidas para el Desarrollo sustentable, 1995. . $^{26}$

El desarrollo sustentable, conforme el paradigma constitucional del art. 41, es aquel que involucra una serie de medidas encaminadas a la administración eficiente y responsable de los recursos naturales por parte del ser humano para la preservación del equilibrio ecológico e implica satisfacer las necesidades de las generaciones presentes sin comprometer las posibilidades de las del futuro para atender sus propias necesidades.

Acompañando los conceptos de consumo y desarrollo sustentable, el objetivo es lograr que los consumidores estén dispuestos aun a pagar más por productos amistosos con el medio ambiente. Este es un fenómeno que se está dando en los países desarrollados donde se ha llegado a un punto en que no solo los consumidores se interesan en que los productos que adquieren reúnan los más altos parámetros de calidad, sino que en su proceso de producción no deterioren el ambiente, en la inteligencia de que "cuanto más sanos sean los productos que consuman, mayor es la posibilidad de disfrutar una mejor calidad de vida". ${ }^{27}$

El desarrollo sustentable es una evolución del antiguo concepto de desarrollo, pues no sólo contempla el progreso económico y material, sino que lo plantea en equilibrio con el bienestar social y el aprovechamiento responsable de los recursos naturales. De este modo, concilia los tres ejes fundamentales de la sustentabilidad: lo económico, lo ecológico y lo social.

Su objetivo último es alcanzar cierto nivel de progreso material sin por ello comprometer el medio ambiente, los recursos naturales o la calidad de vida de los seres humanos y demás especies del planeta.

No obstante, las confusiones economicistas persisten en la actividad científica. Hasta un Premio Nobel en economía como Robert M. Solow ${ }^{28}$ se refiere a la sostenibilidad como un

26 Programa de las Naciones Unidas para el Medio Ambiente. Red de información de consumo y producción sustentables para América Latina y el Caribe: www.redpycs.net

27 Guimaraes, Roberto. Op. cit.

28 Robert M. Solow. "El recurso que le queda al futuro" (conferencia en la Woods Hole Oceanographic Institution). El Espectador. 1995. Robert Merton Solow es un economista estadounidense, nacido en New York, que obtuvo el Premio Nobel de Economía en 1987 por sus contribuciones, precisamente, a la teoría del crecimiento económico. 
concepto esencialmente vago, por tener que ver con nuestra obligación con el futuro. Y advierte, en consecuencia, sobre el peligro de un estancamiento económico y un desaprovechamiento de recursos, si se produce un apego a un conservacionismo ortodoxo. La principal objeción de este economista es — precisamente- que no podemos siquiera imaginarnos cuáles son las necesidades de las generaciones futuras como para determinar cuál debe ser el grado de nuestra utilización de recursos hoy. Reafirma nuestro derecho a complacernos siempre que no sea a expensas del bienestar futuro. Pero ese concepto tiene que tener en cuenta el tipo de medio que vayamos a legar, con su capacidad productiva y su conocimiento tecnológico. Es decir, no debemos asustarnos de consumir algún recurso hoy, si el conocimiento tecnológico va desarrollando algún sustitutivo.

Hay en esto cierto desprecio del sentido del futuro y del compromiso generacional, y una confianza científico-industrial excesiva, no sujeta a prever consecuencias futuras, pensando que necesariamente más adelante se va a estar mejor.

No obstante, contiene criterios axiológicos apreciables. Sostiene el científico ${ }^{29}$ que el futuro no está adecuadamente representado en el mercado, manifestando un claro escepticismo respecto a que este se encargue de cualquier obligación que tengamos con el futuro. El medio ambiente necesita de la protección de las políticas públicas, ya que en su uso irracional se pueden obtener ganancias, cuyo costo asumirán otros.

La industrialización no implica desarrollo ni configura una panacea universal. Puede convertirse en un fenómeno ambientalmente nocivo si no se acompasa con un correcto manejo ecológico. El ambiente "no puede ser contado como una despensa, un almacén, ilimitado, al que se recurre de acuerdo con las necesidades humanas", ${ }^{30}$ de manera que se utilice irracionalmente y comprometa el futuro de las próximas generaciones.

Hoy, el desarrollo económico como concepto ha sido debidamente integrado en una visión humanista formulada por organismos internacionales, dentro de la noción de desarrollo humano.

A su vez, a través de la participación se conecta la visión ambiental con la política. El sistema —basado en la explotación y uso de los recursos naturales y servicios 'ilimitados' que presta la naturaleza a la economía - fue encontrando sus límites en los últimos cuarenta años. Diversas crisis ambientales globales y locales se fueron sucediendo como consecuencia del crecimiento económico e industrial desmedido. Aparecen entonces instituciones gubernamentales para proteger el medio ambiente, leyes y normas. A la vez, la sociedad civil se organiza en agrupaciones con el objeto de promover acciones para la remediación y control de la contaminación hacia la prevención y uso eficiente de los recursos.

29 Ibidem.

30 Andrés Rodríguez. “Qué elige: ¿¿desarrollo o conservación?”. Medio Ambiente. 
Al hablar de sostenibilidad, se está forzado a pensar en equidad. A su vez, como obligación moral, la sostenibilidad es un mandato general, no específico, que "no obliga a preservar esto o aquello, sino a preservar la capacidad de bienestar". ${ }^{31}$

Cuando la economía y los mercados funcionan sin atender pautas ambientales, la sociedad paga altos costos. $Y$ estos se reparten de manera desigual entre sus miembros, que empiezan por desventajas para la salud, trabajo, convivencia y el desarrollo mismo. Así, no cabe duda que el principal peso cae sobre los pobres, que son los más desprotegidos. El sistema de mercado, como mecanismo de asignación de recursos, es completamente ineficaz al no computar este costo a nivel empresa, ni tener o planificar una demanda articulada de recursos ambientales.

Para que política económica y ambiental estén íntimamente ligadas, la categoría ambiental debe figurar en los objetivos y consideraciones económicas. Estos han de dejarse de analizar cuantitativamente y su lugar ocupado por un análisis del crecimiento cualitativo, por un aumento del bienestar general.

La contracara del consumo no sustentable, del lado del proveedor, es la responsabilidad social ambiental, que es un instrumento de autorregulación voluntaria que propone un conjunto de directrices en lo ambiental y lo social para aplicarse en el interior y exterior de las empresas, en función de sus vínculos con los grupos de interés involucrados en el ciclo de vida del producto.

Las empresas manifiestan su voluntad de cumplir con las legislaciones nacionales y las directrices internacionales en lo ambiental y social y la disposición de ir más allá de ellas.

En lo ambiental, aplica un conjunto de métodos y técnicas que contribuyen a minimizar el uso de los recursos naturales; a un uso sustentable de los mismos considerando el principio precautorio y la capacidad del aire, el suelo y el agua de absorber los desechos y los contaminantes, buscando la conservación de los ecosistemas.

En lo social, se refiere a las condiciones laborales (derechos de las personas trabajadoras) y al clima organizacional (enfoque participativo, trabajo en equipo), al igual que el bienestar de la comunidad.

Por eso son pilares del consumo sustentable: ${ }^{32}$

- Satisfacer las necesidades humanas.

- Favorecer una buena calidad de vida por medio de estándares de vida dignos.

31 Robert Solow. Op. cit.

32 Criterio también presente en la Ley 24.240 de Defensa del Consumidor de la Argentina como pauta de política pública en materia de consumo (art. 43, inciso a) y como contenido de educación al consumidor (art. 61, inciso e). 
- Compartir los recursos.

- Actuar tomando en cuenta las generaciones futuras.

- Considerar el impacto de los productos que consumimos a lo largo de toda el ciclo de vida (desde el nacimiento hasta el fin).

- Minimizar el uso de los recursos, los residuos y la contaminación.

\section{Visión económica}

Lo que suceda en el mercado es de directa incidencia en los derechos del consumidor, y en definitiva, en su suerte. El enfoque mercantil nos demuestra que la visión microeconómica o macroeconómica del ámbito en que se lleva a cabo la relación de consumo es imposible de soslayar para un buen diagnóstico, para la correcta aplicación de la legislación y la medición de sus consecuencias.

El derecho del consumidor arraiga en el estudio de cuestiones económicas, y las visiones desde esta disciplina son absolutamente necesarias en el abordaje interdisciplinario que hace falta en la materia. Pero fiel a su espíritu nivelador, los principios de este derecho son refractarios a subordinar al derecho a las leyes de la economía, en el sentido que este solo debe contemplarlas y facilitarlas. El costo-beneficio como parámetro del análisis no puede ser medido únicamente en términos económicos, si ello importa sacrificio de derechos y valores que pueden ser —al menos- axiológicamente superiores al beneficio material. Por ello, los autores advierten que no debe proponerse el "extremismo de la anulación del sistema normativo o su reducción a simple escudero de pretensiones económicas sectoriales, con la consiguiente sepultura de las metas de interés general. Una desviación así importaría una auténtica malversación normativa". ${ }^{33}$

La contracara del economicismo seco, del marketing salvaje y del trato indigno al consumidor es la llamada responsabilidad social empresarial. El sostenimiento y vigencia de la responsabilidad social empresarial y ambiental constituye un desafío que implica construir una contracultura del consumo, del lado del proveedor.

Otro aspecto presente en la relación economía consumo es el de la libertad de contratar.

La libertad de contratar es un derecho inalienable que posee el consumidor, que consiste fundamentalmente en no ser obligado a contratar sobre productos o servicios en los que no recae su elección. Al ser obligado el consumidor a adquirir un bien o servicio como condición

33 Jorge Reynaldo Vanossi. "La aplicación constitucional del análisis económico del Derecho: nada menos y nada más que un enfoque". Anales de la Academia Nacional de Ciencias Morales y Politica, tomo XXXV (2008), parte I, p. 159. 
para adquirir otro, se realiza una verdadera coacción que desvirtúa y afecta la voluntad, "ya que la adquisición del bien o servicio no deseado o no conveniente resulta, por imposición del proveedor, condición sine qua non para la adquisición de lo deseado o necesitado". ${ }^{34}$

Muchos contratos modernos, y ya no tanto, se complementan con otras relaciones contractuales que implican un negocio jurídico complejo e ingresan en la categoría de los contratos conexos, es decir, un conjunto de contratos unidos por una finalidad. ${ }^{35} \mathrm{~A}$ modo de ejemplo, la tarjeta de crédito se complementa en la práctica con sistemas de puntaje o millaje en compañías aéreas, seguros de extracción de cajero, seguros por robo de la tarjeta misma, y sistemas de asistencia al viajero con cobertura de salud, entre otros.

Esos contratos se celebran con distintas personas (organizadas en forma de empresas, comerciantes individuales, o personas físicas o jurídicas) con objetos disímiles, pero vinculadas a un "paquete" o "combo" de servicios, que se ofrecen en forma conjunta a través de publicidades y comunicaciones de beneficios que vinculan a todos los intervinientes, buscando satisfacer (o crear) una demanda múltiple de servicios, publicitándose muchas veces que la contratación del paquete importa la inclusión "sin cargo" de otros servicios, que sin duda están incluidos en el precio calculado del conglomerado, e ilusoriamente se promocionan con precio cero.

De modo que la conexidad contractual converge en un objeto único, aunque los distintos actores del lado del proveedor realicen actividades segmentadas. Todos los involucrados en las prestaciones del paquete se necesitan mutuamente, liquidan, administran o cobran los gastos que hace el consumidor destinados a solventar al otro (hay una finalidad económica común) y se posibilitan entre sí mediante los anuncios y publicidades. Y en ese universo complejo por ellos creado, el consumidor tiene el rol de simple "adherente", frente a un entramado negocial que constituye un decálogo unilateralmente predispuesto respecto del cual debe prestar una adhesión global sin posibilidad de negociar sus cláusulas. En tal tesitura, la interpretación de este tipo de contratos debe efectuarse a favor del no predisponente.

La libertad de contratar consiste en a) la libre opción del individuo entre contratar o no contratar, b) libertad para la elección del otro contratante y c) la posibilidad de dotar de contenido al contrato. ${ }^{36}$

Finalmente, la configuración del mercado como ámbito de participación de múltiples oferentes, o su ausencia, tiene directa influencia en la libertad de elección del consumidor. Esta implica la posibilidad cierta y efectiva de poder escoger entre la variedad y los distintos

34 Flavio Lowenrosen. "Breve visión acerca de la ilegitimidad de las operaciones combo". El Dial. 7 de septiembre, 2007, Suplemento de Derechos de Consumidor.

35 Cámara de Apelaciones en lo Contencioso Administrativo y Tributario de la Ciudad Autónoma de Buenos Aires, sala II

"Citibank N.A. c. Ciudad de Buenos Aires", del 13/05/2004 en La Ley Online, cita: AR/JUR/3645/2004

36 Rubén S. Stiglitz "Un Nuevo orden contractual en el Código Civil y Comercial de la Nación”. La Ley. (2014). 
precios, en un marco de competencia leal. En otro aspecto significa discernimiento, conciencia de derechos y obligaciones, cuyo motor es la educación.

\section{COLOFÓN}

El fenómeno del consumo, a la hora de elaborar, modificar o aplicar derecho para su regulación, debe ser abordado desde un enfoque multidisciplinario, atento a la multiplicidad de problemáticas involucradas.

El enfoque sociológico, en el marco de la globalización en su variedad de significaciones, permite comprender la universalización de los patrones de consumo, las transformaciones tecnológicas y su impacto en la comercialización de bienes y servicios, en particular a través de los emergentes llamados "inducción cultural al consumo" y "obsolescencia programada".

La contemplación política permite descifrar y comprender los procesos de poder y la política de Estado subyacente en los fenómenos de creación, modificación y alcance de normas y garantías en materia de derecho de consumidores y usuarios, como se reseña en el caso argentino desarrollado en el trabajo.

La construcción de la noción de consumidor ciudadano engloba el estudio de la participación política, el rol de las organizaciones gubernamentales y la educación para el consumidor.

Un abordaje ambiental del problema conecta al desarrollo sustentable con su noción hermana de consumo sustentable y lleva a analizar el papel del Estado en la implementación de políticas que pongan en valor estos conceptos. La contracara de las prácticas empresariales prescindentes del consumo sustentable es la responsabilidad social ambiental.

Por último, el aspecto económico no puede ser dejado de tener en cuenta, en razón de que lo que suceda en la macroeconomía o microeconomía de una comunidad repercute en forma directa en la suerte del consumidor, debiéndose tener en cuenta el resguardo de la transparencia del mercado, el libre acceso al mismo, la libertad de contratar y una nueva visión de la contratación de bienes y servicios. La contracara de la visión economicista extrema es la responsabilidad social empresarial.

Como hemos intentado demostrar sumariamente en este ensayo, el Derecho del Consumidor es, citando a Guido Alpa, ${ }^{37}$ "un auténtico laboratorio, en el que el jurista, el economista, el estudioso de la política y de la sociología, así como los estudiosos del lenguaje y de los valores, encuentran una amplia materia de investigación y reflexión”.

37 Guido Alpa. "El derecho de los consumidores: un laboratorio para los juristas". $R C y S$ (2008), p. 109. 


\section{REFERENCIAS}

- Alpa, Guido, "El derecho de los consumidores: un laboratorio para los juristas". $R C y S(2008)$.

- Amartya Sen. "Los tontos racionales: una crítica de los fundamentos conductistas de la teoría económica”. Filosofía y teoría económica. F. Hahn \& M. Hollis. México: FCE, 1986.

- Arias Cáu, Esteban J. - Barocelli, Sergio S. "El sobreendeudamiento del consumidor y la adicción al consumo" Microjuris (octubre 2013), cita: MJ-DOC-6461-AR | MJD6461.

- Condomí, Alfredo Mario. "Primeros pasos en el derecho del consumo. Segunda parte Algunos principios". Recuperado el 8 de febrero de 2015 desde http://www.infojus.gob.ar/ alfredo-mario-condomi-primeros-pasos-derecho-consumo-segunda-parte-dacf130328-201310-25/123456789-Oabc-defg8230-31fcanirtcod

- García Canclini, Néstor. Consumidores y ciudadanos. Conflictos multiculturales de la globalización. México: Grijalbo, 2000.

- Guimaraes, Roberto P. "Modernidad, medio ambiente y ética: los dilemas del desarrollo". Ambiente \& Sociedade, 2 (1998, primer semestre), pp. 5-24

- Leiva Fernández, Luis F. P. "La Ley 26.361 de afuera hacia adentro”. Suplemento Especial La Ley "Reforma de La Ley de Defensa del Consumidor" (abril de 2008), p. 67 y siguientes.

- Lowenrosen, Flavio. "Breve visión acerca de la ilegitimidad de las operaciones combo". El Dial. 7 de septiembre, 2007, Suplemento de Derecho del Consumidor.

- Pablo Facioni, Sebastián. "El veto y promulgación parcial a la ley de defensa del consumidor y del usuario es inconstitucional, tanto en su aspecto formal como sustancial". El Dial. 5 de mayo, 2006, Suplemento de Derechos de Consumidor.

- Rodríguez, Andrés. “Qué elige: ¿desarrollo o conservación?”. Medio Ambiente.

- Solow, Robert M. "El recurso que le queda al futuro" (conferencia en la Woods Hole Oceanographic Institution). El Espectador. 1995.

- Vanossi, Jorge Reynaldo. "La aplicación constitucional del análisis económico del Derecho: nada menos y nada más que un enfoque". Anales de la Academia Nacional de Ciencias Morales y Politica, tomo XXXV (2008), parte I.

Recibido: 19/03/2015

Aprobado: 07/04/2015 